\title{
Spike Timing of Distinct Types of GABAergic Interneuron during Hippocampal Gamma Oscillations In Vitro
}

\author{
Norbert Hájos, ${ }^{1}$ János Pálhalmi, ${ }^{1}$ Edward 0. Mann, ${ }^{2}$ Beáta Németh, ${ }^{1}$ Ole Paulsen, ${ }^{2}$ and Tamas F. Freund ${ }^{1}$ \\ ${ }^{1}$ Institute of Experimental Medicine, Hungarian Academy of Sciences, Budapest H-1450, Hungary, and 2Department of Physiology, University of Oxford, \\ Parks Road, Oxford OX1 3PT, United Kingdom
}

\begin{abstract}
Gamma frequency $(30-100 \mathrm{~Hz})$ network oscillations occur in the intact hippocampus during awake, attentive behavior. Here, we explored the underlying cellular mechanisms in an in vitro model of persistent gamma-frequency oscillations, induced by bath application of $20 \mu \mathrm{M}$ carbachol in submerged hippocampal slices at $30 \pm 1{ }^{\circ} \mathrm{C}$. Current-source density analysis of the field oscillation revealed a prominent alternating sink-source pair in the perisomatic and apical dendritic regions of CA3. To elucidate the active events generating these extracellular dipoles, we examined the firing properties of distinct neuron types. Visually guided unit recordings were obtained from individual CA3 neurons followed by intracellular labeling for anatomical identification. Pyramidal cells fired at $2.82 \pm 0.7 \mathrm{~Hz}$, close to the negative peak of the oscillation $(0.03 \pm 0.65 \mathrm{msec})$, and often in conjunction with a negative spike-like component of the field potential. In contrast, all phase-coupled interneurons fired after this negative peak. Perisomatic inhibitory interneurons fired at high frequency $(18.1 \pm 2.7 \mathrm{~Hz})$, shortly after the negative peak $(1.97 \pm 0.95 \mathrm{msec})$ and were strongly phase-coupled. Dendritic inhibitory interneurons fired at lower frequency $(8.4 \pm 2.4 \mathrm{~Hz})$ and with less fidelity and a longer delay after the negative peak $(4.3 \pm 1.1 \mathrm{msec})$, whereas interneurons with cell body in the stratum radiatum often showed no phase relationship with the field oscillation. The phase and spike time data of individual neurons, together with the current-source density analysis, support a synaptic feedback model of gamma oscillations primarily involving pyramidal cells and inhibitory cells targeting their perisomatic region.
\end{abstract}

Key words: hippocampus; carbachol; gamma oscillation; GABAergic cells; phase-coupling; rat

\section{Introduction}

Oscillatory activity in the gamma-frequency band $(30-100 \mathrm{~Hz})$ occurs in multiple brain regions and has been implicated in different cognitive functions, including sensory processing (Singer, 1993; Gray, 1994), selective attention (Fries et al., 2001), and memory (Fell et al., 2001). Gamma oscillations are prominent in the hippocampal formation (Leung, 1979; Bragin et al., 1995; Chrobak and Buzsáki, 1998; Csicsvari et al., 2003), where they have been suggested to contribute to encoding and retrieval of memory (Hasselmo et al., 1996; Varela et al., 2001). Despite extensive investigation of gamma oscillations in vivo, the cellular mechanisms underlying the generation and maintenance of this network activity are largely unknown.

The hippocampal circuitry comprises excitatory principal cells and inhibitory interneurons. The former cell type is thought to encode, process, store, and retrieve information (cf. Engel et al., 2001), whereas the latter controls spike timing of principal neurons, synaptic plasticity, and network oscillations (Buzsáki

\footnotetext{
Received June 1, 2004; revised Aug. 12, 2004; accepted Aug. 31, 2004.

This work was supported by Országos Tudományos Kutatási Alapprogramok (Grant T046820), the Howard Hughes Medical Institute, National Institutes of Health Grant NS30549, the Biotechnology and Biological Sciences Research Council, and the British Council. N.H. is a grantee of the Bolyai János Scholarship. We thank Dr. V. Varga for helping in data analysis. The technical assistance of Katalin Lengyel is gratefully acknowledged.

Correspondence should be addressed to Norbert Hájos, Department of Cellular and Network Neurobiology, Institute of Experimental Medicine, Hungarian Academy of Sciences, Szigony u. 43, Budapest 1083, Hungary. E-mail: hajos@koki.hu.

DOI:10.1523/JNEUROSCI.2113-04.2004

Copyright $\odot 2004$ Society for Neuroscience $\quad 0270-6474 / 04 / 249127-11 \$ 15.00 / 0$
}

and Chrobak, 1995; Paulsen and Moser, 1998; Whittington and Traub, 2003). Although principal neurons are rather uniform within each hippocampal subfield, a large morphological and functional heterogeneity is typical of GABAergic interneurons (Freund and Buzsáki, 1996). Functionally, at least three main GABAergic cell types coexist in cortical networks: perisomatic inhibitory neurons controlling the firing of principal cells, dendritic inhibitory interneurons regulating synaptic input and $\mathrm{Ca}^{2+}$ signaling, and GABAergic cells specifically innervating other inhibitory interneurons (Gulyás et al., 1996; Miles et al., 1996). Information about the activity of different types of interneuron during oscillations should facilitate our understanding of how these network oscillations are generated, and may shed light on their different functions. To date, the firing patterns of some anatomically identified cell types have been correlated with $\theta$ and ripple oscillations, but not to gamma oscillations. Moreover, only a limited number of neurons from each cell class has been reported (Soltesz et al., 1993; Sik et al., 1995; Ylinen et al., 1995; Klausberger et al., 2003, 2004).

To study the cellular mechanisms underlying gamma activity, in vitro models of gamma oscillation have been introduced (Whittington et al., 1995; Fisahn et al., 1998). Cholinergically induced gamma-frequency network oscillations in hippocampal slices (Fisahn et al., 1998) are a model of hippocampal gamma oscillations during wakefulness, when extracellular acetylcholine levels are high (Marrosu et al., 1995). Similar to in vivo gamma oscillations, these in vitro oscillations are generated within the 
CA3 subfield, and at each oscillatory cycle pyramidal cell firing is followed by the discharge of local GABAergic interneurons (Bragin et al., 1995; Csicsvari et al., 2003).

The aim of this study was to investigate the firing properties of different types of anatomically identified hippocampal neuron in the CA3 region during cholinergically induced gamma oscillations in vitro. We were able to record persistent gamma oscillations in the submerged slice allowing a more detailed investigation of the mechanisms underlying synchronous activity. Using visually guided single-unit and patch-clamp recordings during these persistent network oscillations, we compared the firing activity and spike timing of distinct types of interneuron and pyramidal cells.

\section{Materials and Methods}

Slice preparation. All experiments were performed in accordance with British and Hungarian legislation and institutional guidelines. Male Wistar rats [postnatal day 14 (P14)-P20] were deeply anesthetized with isoflurane. After decapitation, the brain was quickly removed and placed into ice-cold artificial CSF (ACSF) containing (in mM): sucrose, 252; $\mathrm{KCl}$, 2.5; $\mathrm{NaHCO}_{3}, 26 ; \mathrm{CaCl}_{2}, 2 ; \mathrm{MgCl}_{2}, 2 ; \mathrm{NaH}_{2} \mathrm{PO}_{4}, 1.25$; glucose, 10, and bubbled with $95 \% \mathrm{O}_{2}$ and $5 \% \mathrm{CO}_{2}$ (carbogen gas). We prepared 400 $\mu \mathrm{m}$-thick horizontal slices using a Leica (Nussloch, Germany) VT1000S microtome. Slices containing the hippocampal formation were trimmed from other brain regions and kept in an interface-type holding chamber at room temperature for at least $60 \mathrm{~min}$ before recording.

Electrophysiological recordings and data analysis. Experiments were performed in the $\mathrm{CA} 3$ region of the hippocampus using a submergedtype recording chamber at $30 \pm 1^{\circ} \mathrm{C}$. Extracellular solution had content as above, but with $126 \mathrm{~mm} \mathrm{NaCl}$ instead of sucrose. The solution, constantly bubbled with carbogen gas at room temperature, was superfused at a flow rate of at least $3.5-4.5 \mathrm{ml} / \mathrm{min}$, crucial for oscillations in submerged slices (Hájos et al., 2004). Oscillations were induced by bath application of $20 \mu \mathrm{M}$ carbachol, which was present throughout the experiments (Sigma, St. Louis, MO). Two patch pipettes filled with ACSF (resistance 3-6 M $\Omega$ ) were used during the recording. The tip of one electrode was placed within the pyramidal cell layer of the CA3b region at a depth of 100-200 $\mu \mathrm{m}$ to monitor extracellular field oscillations. The other pipette was used to detect action potentials extracellularly from a visually identified neuron. Recorded neurons located no deeper than $100-120 \mu \mathrm{m}$ from the surface were sampled in the close vicinity $(<200$ $\mu \mathrm{m}$ ) of the field electrode, but for some cells in the stratum radiatum the distance between the electrodes exceeded $300 \mu \mathrm{m}$. After the extracellular recording, the same cell was labeled with a different pipette using the whole-cell patch-clamp technique. For intracellular labeling, this pipette contained (in $\mathrm{mm}$ ): $138 \mathrm{~K}$-gluconate, $2 \mathrm{NaCl}, 10$ creatine phosphate, 10 HEPES, 4 ATP, 0.4 GTP, and $0.3-0.5 \%$ biocytin. Only recordings obtained extracellularly were analyzed in this work. All data were recorded with a Multiclamp 700A amplifier (Axon Instruments, Foster City, CA), except signals for current-source density (CSD) analysis, which were acquired on a planar multielectrode array using the Panasonic (Matsushita, Osaka, Japan) MED64-system (Oka et al., 1999). Multielectrode recordings were performed with an $8 \times 8$ array of planar microelectrodes, each $20 \times 20 \mu \mathrm{m}$ in size, with an interpolar distance of $100 \mu \mathrm{m}$ (MED-P2105, Panasonic; Tensor Biosciences, Irvine, CA). Slices were positioned on the array and maintained in a submerged condition. ACSF containing $20 \mu \mathrm{M}$ carbachol, bubbled with carbogen, was superfused at 4-6 $\mathrm{ml} / \mathrm{min}$. Signals were low-pass filtered at $2 \mathrm{kHz}$ for both field and unit recordings. Data acquisition was done with a PCI-6024E board (National Instruments, Austin, TX) using either EVAN 1.3 (courtesy of Dr. I. Mody, Departments of Neurology and Physiology, University of California Los Angeles, Los Angeles, CA) or IGOR (WaveMetrics, Lake Oswego, OR) software and analyzed offline using Origin 7.0, Igor Pro 4.0, and Matlab 6.0 software. For investigation of stability of oscillations in submerged slices, power spectra were estimated from 1-min-long traces with the Welch method using 1-sec-wide time windows with $50 \%$ overlap. Peak frequencies and summated power in the frequency range of 20-47
$\mathrm{Hz}$ were used for comparison. Peak-to-peak averages were made by averaging successive peak-to-peak signals interpolated to a 100-point wave. One-dimensional CSD profiles were calculated as the second spatial derivative of these peak-to-peak averages. To examine the firing properties of neurons relative to the ongoing field oscillation, stationary 1- to 3-min-long recording epochs were analyzed, to collect a minimum of 200 spikes. Absolute spike times were calculated using threshold detection for high-pass filtered $(>100 \mathrm{~Hz})$ single-unit recordings, with spike detection threshold adjusted by visual inspection. Spike timing was analyzed using spike time histograms, calculated relative to the negative peak of the peak-to-peak averages. Because in several examples spike time distributions showed clear asymmetry, the mode of the histograms was used for the comparison. To enable comparison of our in vitro data with those obtained in freely moving animals (Csicsvari et al., 2003), spike phase was calculated relative to the negative peak of a cycle of the bandpass-filtered field recording in the frequency range of $15-45 \mathrm{~Hz}$ using a high-order digital Finite Impulse Response (FIR) filter. Field signal was filtered in both directions to conserve the phase of the oscillations. Phase values of individual cells were analyzed by circular statistical methods using Oriana 2.0 software (Kovach Computing Services, Anglesey, UK). Significant deviation from uniform (random) phase distribution along the circle indicates directionality. This was tested with Rao's spacing test and Rayleigh's uniformity test (both calculates the probability of the null hypothesis that the data are distributed in a uniform manner). To characterize a nonuniform distribution, two parameters of its mean vector (calculated from individual observations) were used, i.e., the mean angle and the length of the mean vector. The length, a measure of disparity, ranges from 0 to 1 ; larger values indicate that the observations are clustered more closely around the mean than lower ones. To illustrate the precision of spiking during oscillations, we used values of angular SD, where lower numbers indicate stronger phase-coupling. Note that field oscillations recorded at $2 \mathrm{kHz}$ and the peak-to-peak averages (used for calculation of spike times) clearly deviated from the sinusoidal waveforms obtained after bandpass filtering of field signals (used for calculation of spike phases). Because of this difference, the negative peaks of the peak-to-peak averages $(0 \mathrm{msec})$ and the bandpass filtered signals $\left(0^{\circ}\right)$ did not correspond to each other (see Fig. 3). Data are presented as mean \pm SEM. Statistical significance was assessed using $t$ test $(p<0.05)$.

Anatomical identification of cells. After intracellular recording and biocytin filling, the slices were fixed in $4 \%$ paraformaldehyde in $0.1 \mathrm{M}$ phosphate buffer (PB; pH 7.4) for at least $30 \mathrm{~min}$, followed by washout with $\mathrm{PB}$ several times, and incubation in cryoprotecting solution (30\% sucrose in $0.01 \mathrm{M} \mathrm{PB}$ ) for $2 \mathrm{hr}$. Then slices were freeze-thawed three times above liquid nitrogen and treated with $1 \% \mathrm{H}_{2} \mathrm{O}_{2}$ in $\mathrm{PB}$ for 15 min to reduce endogenous peroxidase activity. Filled cells were visualized using avidin-biotinylated horseradish peroxidase complex reaction (ABC; Vector Laboratories, Burlingame, CA) with nickel-intensified 3,3'diaminobenzidine (Sigma) as chromogen giving a dark blue reaction product. After dehydration and embedding in Durcupan, representative neurons were reconstructed with the aid of a drawing tube using a 40 or $63 \times$ objective.

\section{Results}

Persistent network oscillations at gamma frequency were induced in hippocampal slices under submerged condition by bath application of $20 \mu \mathrm{M}$ carbachol (Fig. 1A). Network oscillations were monitored by an extracellular recording electrode in the pyramidal cell layer of the CA3b region. First, we characterized the properties and temporal stability of carbachol-induced gamma oscillations under these conditions. Both the frequency $(34.6 \pm 0.9 \mathrm{~Hz})$ and the gamma-band power $\left(9.2 \pm 1.2 \times 10^{-9}\right.$ $\left.\mathrm{V}^{2} ; n=6\right)$ of the oscillations, which showed only minor fluctuations during the recording period (up to $1 \mathrm{hr}$ ) (Fig. $1 \mathrm{~B}$ ), were comparable with those reported earlier in interface chamber (Fisahn et al., 1998; Pálhalmi et al., 2004). Thus, gamma oscillations with properties similar to those found under interface conditions can be investigated in submerged slices. 
A
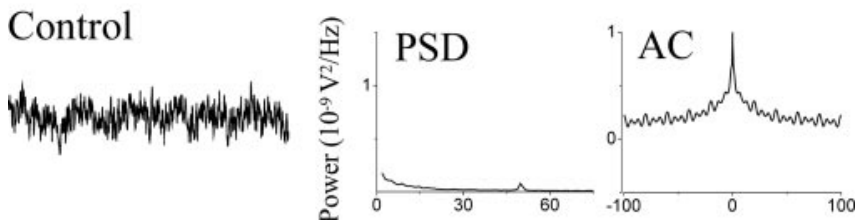

$10 \mathrm{~min}$ maventhy

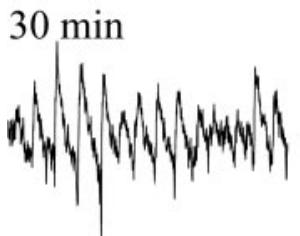

$60 \mathrm{~min}$

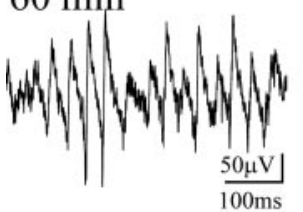

B

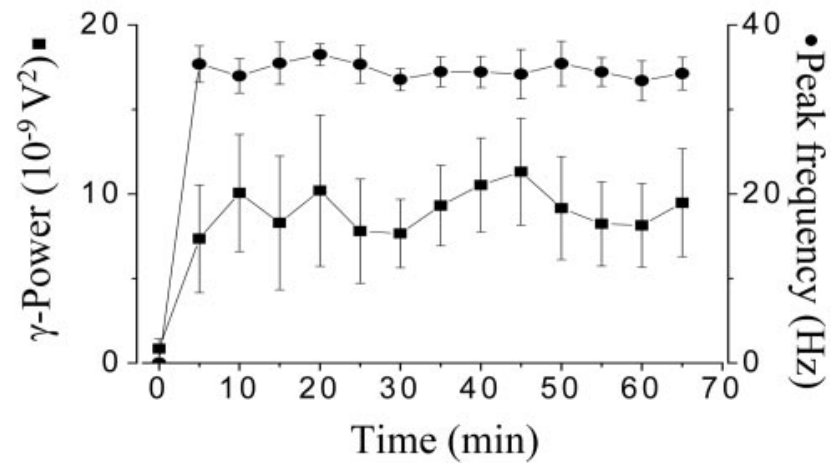

Figure 1. Carbachol-induced gamma oscillations in submerged hippocampal slices. $A, A$ representative experiment of synchronous activity after bath application of $20 \mu \mathrm{m}$ carbachol, a cholinergic agonist, demonstrating the temporal stability of the oscillation. Field potential recordings were obtained in the stratum pyramidale of the CA3 hippocampal region. During the control period, no rhythmicity can be seen. Drug application induced a stable oscillation in 10 min that was sustained for at least $1 \mathrm{hr}$. Corresponding power spectra (PSD) and autocorrelation (AC) of the recordings at different time points were calculated from 1-min-long epochs. $B$, Stability of the gamma oscillations (gamma power, square; peak frequency, circle) in submerged slices illustrated on a summary graph obtained from six different experiments. Data points represent mean $\pm \mathrm{SEM}$.

Next, we performed CSD analysis of the carbachol-induced field oscillation acquired on a 64-channel planar multielectrode probe organized in an 8-by-8 array (interelectrode center-tocenter distance of $100 \mu \mathrm{m})($ Fig. $2 A)$. The peak frequency of the oscillations was $31.6 \pm 2.1 \mathrm{~Hz}(n=5)$ (Fig. $2 B)$. The largestamplitude oscillations in local field potentials were recorded in the proximal stratum radiatum (Fig. $2 C$ ) with clear phase reversal compared with oscillations in the stratum pyramidale as seen on the corresponding peak-to-peak averages (Fig. 2D). The CSD analysis uncovered sink-source pairs in strata radiatum and pyramidale that were alternating periodically (Fig. $2 D$ ), similar to what has been reported in vivo (Bragin et al., 1995; Csicsvari et al.,
A

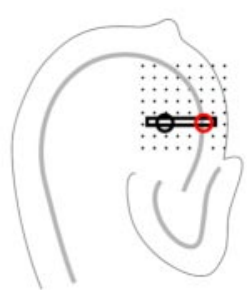

B
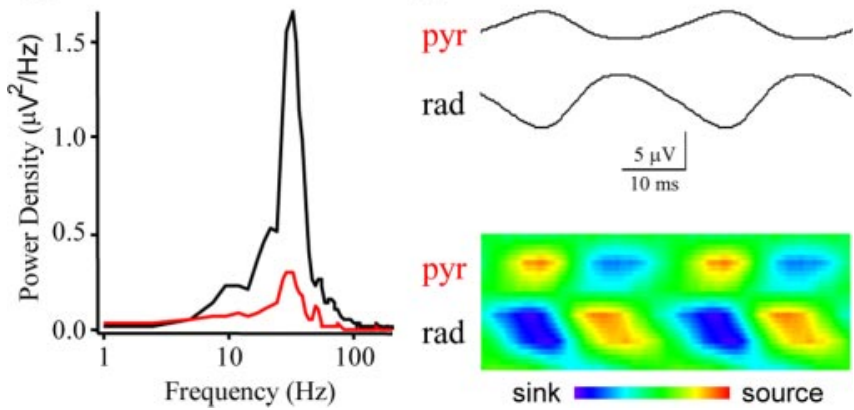

Figure 2. CSD analysis of cholinergically induced oscillations in submerged slices. A, Network oscillations induced by $20 \mu \mathrm{m}$ carbachol were recorded across the CA3 subfield from slices mounted on 64-electrode arrays. The sample recordings from the stratum pyramidale and stratum radiatum shown in (and $D$ were taken from the electrodes marked by the red and black circles, respectively. The black box marks the electrodes used for calculating the current source density profile in $D$. $B$, The power spectral density functions of the field oscillation in the stratum pyramidale (red) and stratum radiatum (black) both revealed peaks at $32 \mathrm{~Hz}$. C, Example traces from the stratum pyramidale (top) and stratum radiatum (bottom) show a clear reversal in the polarity of the field oscillation between these layers. D, Peak-to-peak cycle averages were calculated for the gamma-frequency oscillations, using a reference from the stratum pyramidale (marked with red circle in $A$ ). The average period was $29 \mathrm{msec}$. The peak-to-peak averages were used to construct CSD profiles for the gamma-frequency oscillations, which revealed alternating sink (blue) and source (red) pairs in the stratum pyramidale and stratum radiatum.

2003). This CSD profile raises the question of whether different sources could be produced by distinct sets of interneurons with different laminar and target selectivity of their axon terminals. We therefore performed a detailed analysis of the spiking properties of distinct types of interneurons, with identified axonal and dendritic arbors, relative to ongoing gamma-frequency network oscillations.

After induction of stable network oscillations, action potentials were recorded extracellularly from visually identified neurons followed by intracellular labeling via a different patch pipette to enable post hoc anatomical identification. Results are reported only for those neurons that could be unequivocally classified based on their synaptic input and output characteristics (i.e., dendritic and axonal arborizations) $(n=54$ from a total of 101 recorded neurons).

Relative to the extracellularly recorded field oscillation, all pyramidal cells ( $n=10$ of 10$)$ and a proportion of interneurons ( $n=31$ of 44$)$ showed phase-related firing. Two different methods were used to quantify the phase-related firing. First, a peakto-peak average of the oscillation was made between consecutive negative peaks, and a spike time histogram constructed based on the spike timing relative to each peak-to-peak interval, normalized to the overall mean length of the peak-to-peak interval. Second, to facilitate comparison to earlier reports in vivo (Csicsvari et al., 2003), the field oscillation was bandpass-filtered between 15 and $45 \mathrm{~Hz}$ and the phase of firing was calculated relative to the negative peak of the bandpass-filtered oscillation. The phase histogram of those cells that could not be distinguished from a uniform distribution using both Rayleigh's uniformity test and Rao's 


\section{A Pyramidal cell B Interneuron}

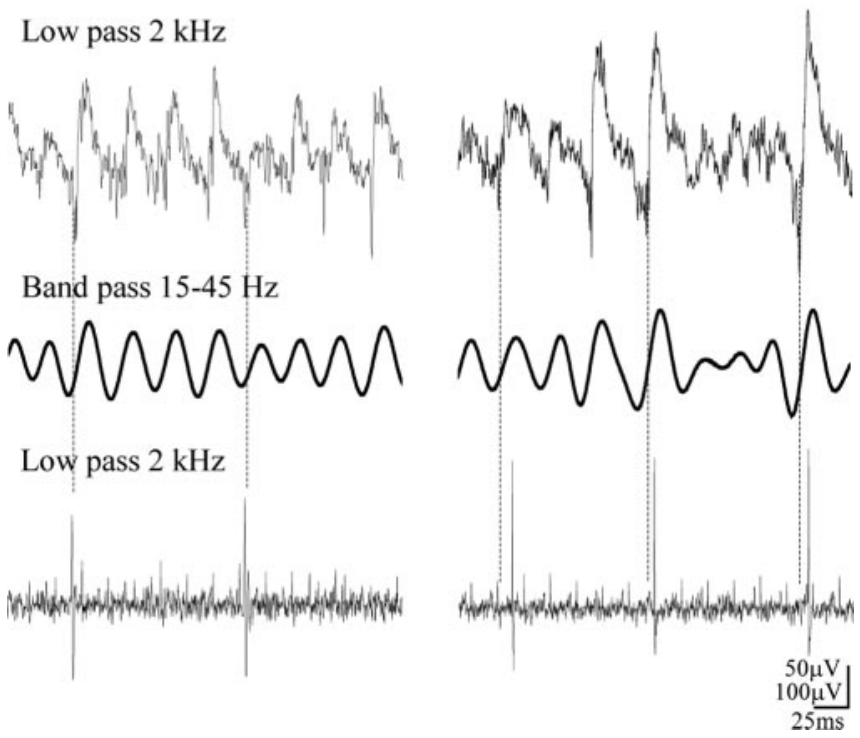

Figure 3. Cholinergically induced gamma oscillations in the pyramidal cell layer consist of slow and fast components. Field recordings low-pass-filtered at $2 \mathrm{kHz}$ contain an oscillatory component, which is often decorated at the negative part with spike-like elements (top row). For the detailed analysis of gamma oscillations, traces were bandpass filtered in the frequency range of $15-45 \mathrm{~Hz}$ using a high-order FIR filter in both directions to conserve the phase of the oscillation. Note that negative peaks of the oscillation on filtered signals are shifted compared with those seen in the raw recordings (dashed line). Comparison of unit recordings during oscillations obtained from a pyramidal cell $(A)$ and from an interneuron [post hoc identified as an 0 LM cell $(B)$ ] revealed that firing of the pyramidal cell took place at the negative peak of the gamma oscillation (dashed line), whereas the OLM cell discharged with a short delay (bottom row).

spacing test were classified as nonphase-coupled neurons and not included in the further analysis.

Pyramidal cells fired action potentials around the negative peak of the oscillations with an average spike time of $0.03 \pm 0.65$ msec after the negative peak $(n=10)$ (Figs. $3 A, 4 A)$. The field oscillation as recorded in the pyramidal cell layer was regular but deviated significantly from a purely sinusoidal waveform. On a proportion of cycles, a variable negative spike-like component followed by a positive wave was observed. Pyramidal neuron firing tended to be close to the negative peak of the oscillation, coinciding with this spike-like component when present, suggesting that these spikes of the field recording reflect population discharges of pyramidal cell ensembles of variable size (Fig. 3A). All pyramidal neurons showed significant phase-coupling (length of the mean vector calculated from the phase histograms for each cell $>0.2, p<0.05$, Rao's spacing test and Rayleigh's uniformity test). The mean angle of their spike times relative to the bandpass-filtered field signal was $58.1 \pm 5.3^{\circ}$ (mean $\pm 95 \%$ confidence interval). The phase coupling of pyramidal cells was weaker than that of the majority of interneurons, as indicated by an angular SD of $59.1 \pm 6.1^{\circ}$ (Fig. $4 A$ ). The average frequency of pyramidal cell firing was $2.82 \pm 0.7 \mathrm{~Hz}$ (Fig. $4 A$ ). Because the spiking of phase-coupled cells varies with the oscillation frequency, we divided the firing rate with the oscillation frequency to compare the activity of different cell types. For the pyramidal cells, the firing rate divided by the oscillation frequency was $0.09 \pm 0.02$ (i.e., these neurons fired on fewer than every 10th cycle of the oscillation).
Relative to the pyramidal cells, all interneurons that were phase-coupled to the oscillation fired significantly later, on the ascending phase of the field potential, as recorded in the pyramidal cell layer (Figs. 3B, 4B, C, 5, 6). Perisomatic inhibitory cells were the most abundant cell group among the sampled interneurons $(n=14$ of 31$)$. Among them, 12 basket cells and 2 putative axo-axonic cells were distinguished based on their axonal arborizations. Both cell types had either multipolar or bitufted dendritic tree. The axon of the basket cells arborized rather evenly in the stratum pyramidale with some collaterals penetrating into strata oriens and lucidum, and only occasionally into the stratum radiatum (Fig. $4 \mathrm{~B}$ ), whereas axon branches of the putative axoaxonic cells were restricted to the bottom part of the stratum pyramidale and the top part of the stratum oriens, often giving rise to short bouton-laden collaterals with vertical or oblique orientation (Fig. 4C). Because some axo-axonic cells might have been misclassified as basket cells, and we were unable to provide electron microscopic evidence to unequivocally identify the two putative axo-axonic cells, we decided to pool data from all perisomatic inhibitory cells and analyze them together. One example for each cell type is shown in Figure 4, $B$ and $C$. Eleven of fourteen perisomatic inhibitory neurons showed significant phase coupling (length of the mean vector $>0.2 ; p<0.05$; Rao's spacing test and Rayleigh's uniformity test) (Fig. $7 B, C$ ). In comparison with other cell types, the perisomatic inhibitory cells discharged action potentials at a high rate $(18.1 \pm 2.7 \mathrm{~Hz})($ Fig. $7 A, G)$. The spike rate divided by the oscillation frequency was $0.62 \pm 0.09$ for this cell type (Fig. 7D), meaning that on average they fired on more than every second cycle of the oscillation. Their average spike time was $1.97 \pm 0.95 \mathrm{msec}$ after the negative peak of the oscillation (Figs. $4 B, C, 8 A, C$ ). Relative to the bandpass-filtered oscillation signal, the average phase of firing was $93 \pm 2.1^{\circ}(n=$ 11) (Fig. $7 E, G)$. The firing of perisomatic inhibitory cells was tightly coupled to the oscillation, as shown by a mean angular SD of $51.1 \pm 5^{\circ}$ (Figs. $4 B, C, 7 F$ ). Correlation of discharge frequency with spike times indicated that more active cells tended to fire earlier on an oscillation cycle $(r=-0.581 ; p=0.06)$ (Fig. $8 B)$. In one putative axo-axonic and three basket cells, two spikes per cycle ("doublets") were often observed.

Among the dendritic inhibitory cells, we classified OLM cells (interneurons with dendritic tree in stratum oriens and axonal projection into stratum lacunosum-moleculare) (Fig. 5A), radiatum cells (RCs) (both the dendritic and axonal arborization localized in the stratum radiatum) (Fig. 5B), and RLM cells (dendritic tree found primarily in stratum radiatum with axon restricted to stratum lacunosum-moleculare) (Fig. 5C). The firing properties of dendritic inhibitory neurons varied between these subtypes. All but one OLM cell was phase-coupled ( $n=4$ of 5) (Fig. $7 B)$. Their discharge rate was relatively high $(12.9 \pm 1.8$ $\mathrm{Hz}$ ) (Figs. $5 A, 7 A$ ). Spike rate divided by oscillation frequency was $0.4 \pm 0.07$ (Fig. $7 D$ ), i.e., these cells fired on almost every second cycle of the oscillation. Their spikes also occurred after the negative peak of the oscillations with an average spike time of $2.95 \pm$ $0.44 \mathrm{msec}$ after the negative peak (Fig. $8 A, C$ ). The mean angle of the firing (obtained from the filtered signal) was $88.1 \pm 6.1^{\circ}$ (Fig. $7 E, G)$. The phase coupling of OLM cells showed large variability with a mean angular SD of $59.8 \pm 14.5^{\circ}$ (Figs. $5 A, 7 F$ ). Radiatum cells showed the most heterogeneous behavior. Only three of seven radiatum cells showed significant phase-coupling (Fig. 7B). These radiatum cells had the lowest firing rate among all neurons $(2.3 \pm 0.6 \mathrm{~Hz}, n=3$ ) (Figs. 5B, 7A, G) as also indicated by their spike rate divided by oscillation frequency $(0.07 \pm 0.02)$ (Fig. $7 D$ ). Of all cells recorded, the radiatum cells discharged with the 
A
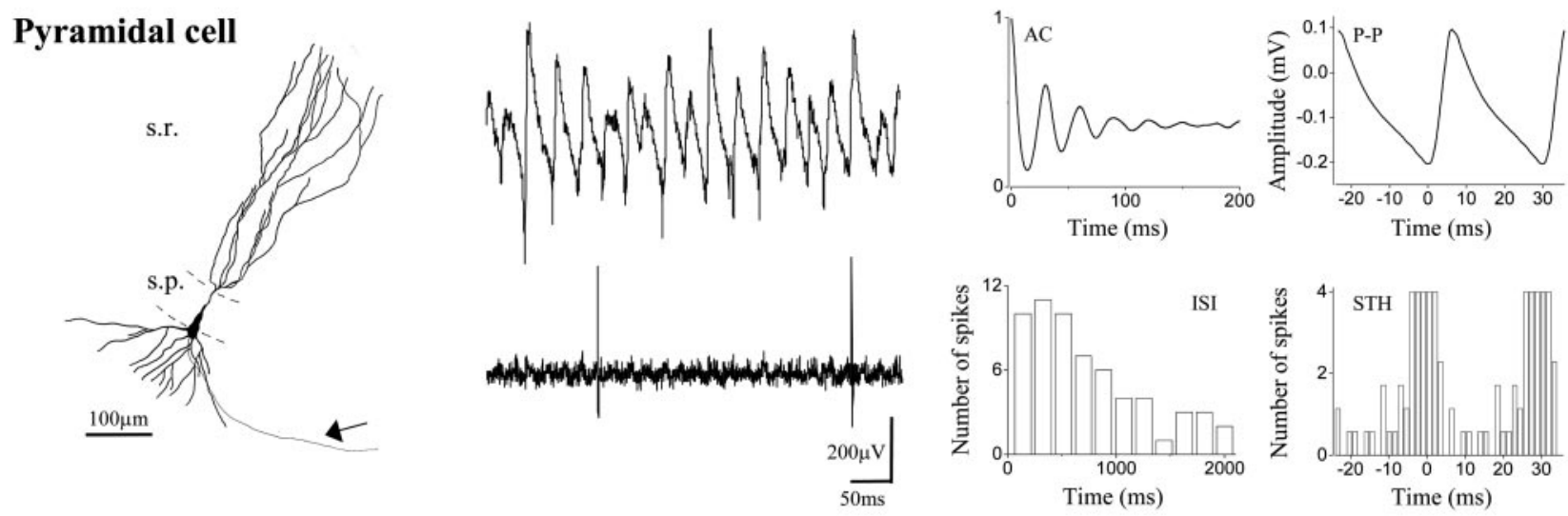

B

\section{Perisomatic inhibitory cell}
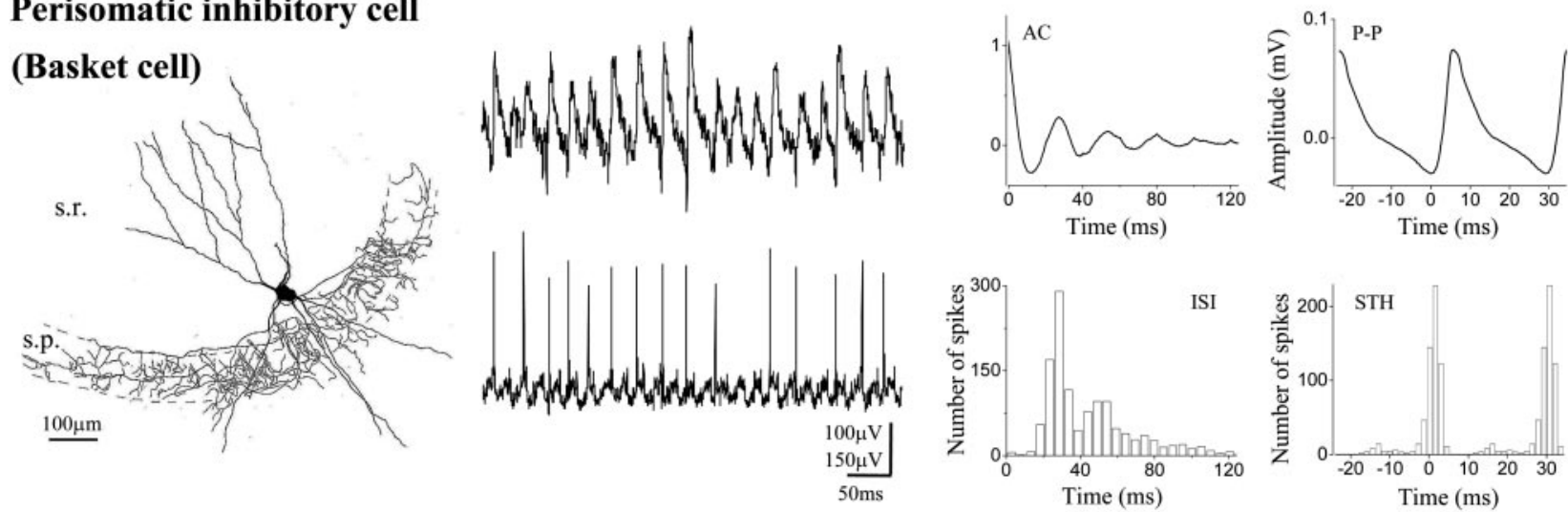

C

\section{Perisomatic inhibitory cell}

\section{(Putative axo-axonic cell)}
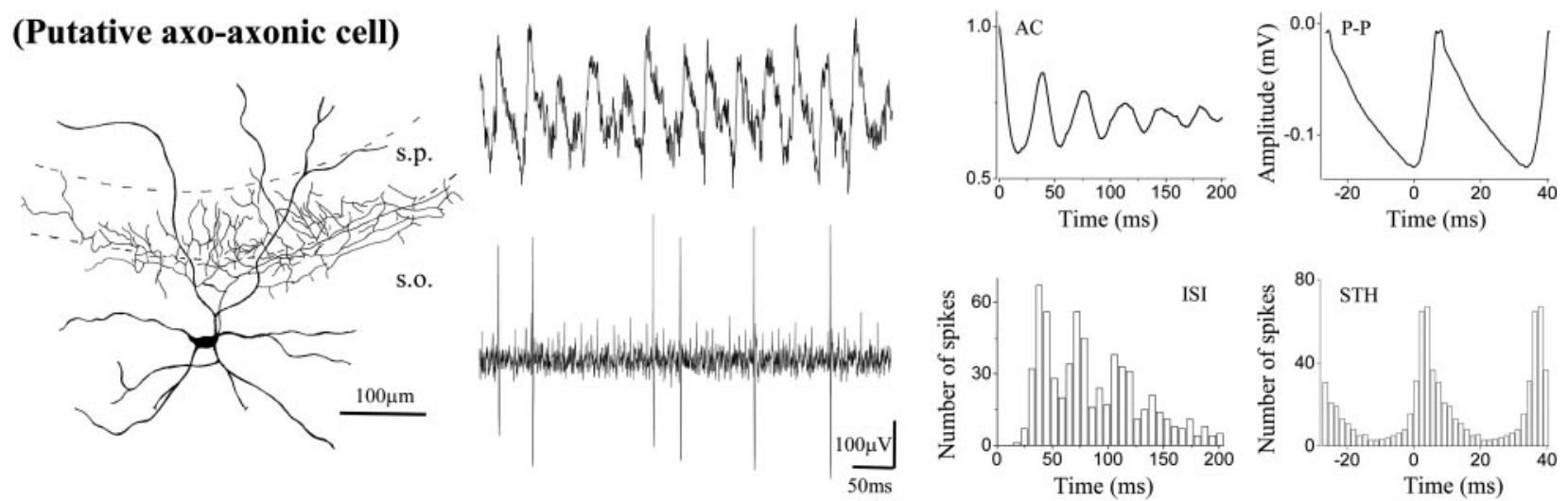

Figure 4. Firing properties of pyramidal cells and perisomatic inhibitory neurons during cholinergically induced gamma oscillations. Camera lucida reconstructions of intracellularly labeled neurons are shown in the left column. A, Pyramidal cell located at the border of strata pyramidale and oriens had an extensive dendritic arborization outside the pyramidal cell layer. In this case, only the main axon projecting toward the fimbria-fornix (arrow) could be followed. $B$, Multipolar basket cell with soma in the stratum lucidum gave rise to a dense axonal ramification almost completely restricted to the stratum pyramidale. C, A putative axo-axonic cell with axon collaterals at the border of strata pyramidale and oriens, showing short vertical and oblique axon segments studded with boutons. The cell body and the large part of the dendritic arbor were found in the stratum oriens, but some dendrites also penetrated into the strata pyramidale and lucidum. The middle panel of the figure shows representative traces for each cell illustrating the different firing activity during gamma oscillations. The pyramidal cell discharged at $1.1 \mathrm{~Hz}$, the basket cell at $22.8 \mathrm{~Hz}$, and the axo-axonic cell at $11.8 \mathrm{~Hz}$. The right panels show autocorrelograms (AC), interspike interval histograms (ISI), peak-to-peak averages (P-P), and spike time histograms (STH) for each cell type calculated from a 3-min-long epoch for the pyramidal cell and from 1-min-long epochs for interneurons. Spike time histograms show that the pyramidal cell fired at the negative peak of the oscillations, whereas interneurons fired with a short delay. Note that perisomatic inhibitory cells follow the oscillations with high fidelity, as can be seen by comparing the ISI histograms with the autocorrelograms. s.r., Stratum radiatum; s.p., stratum pyramidale; s.o., stratum oriens. 
A

\section{OLM cell}
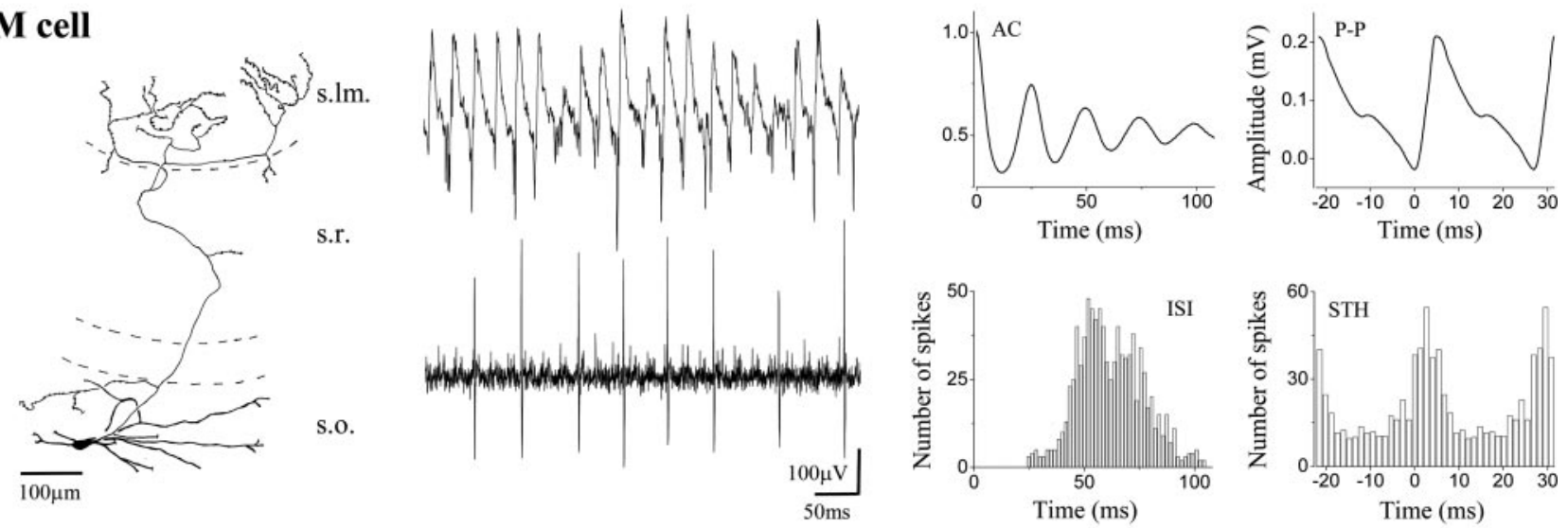

B
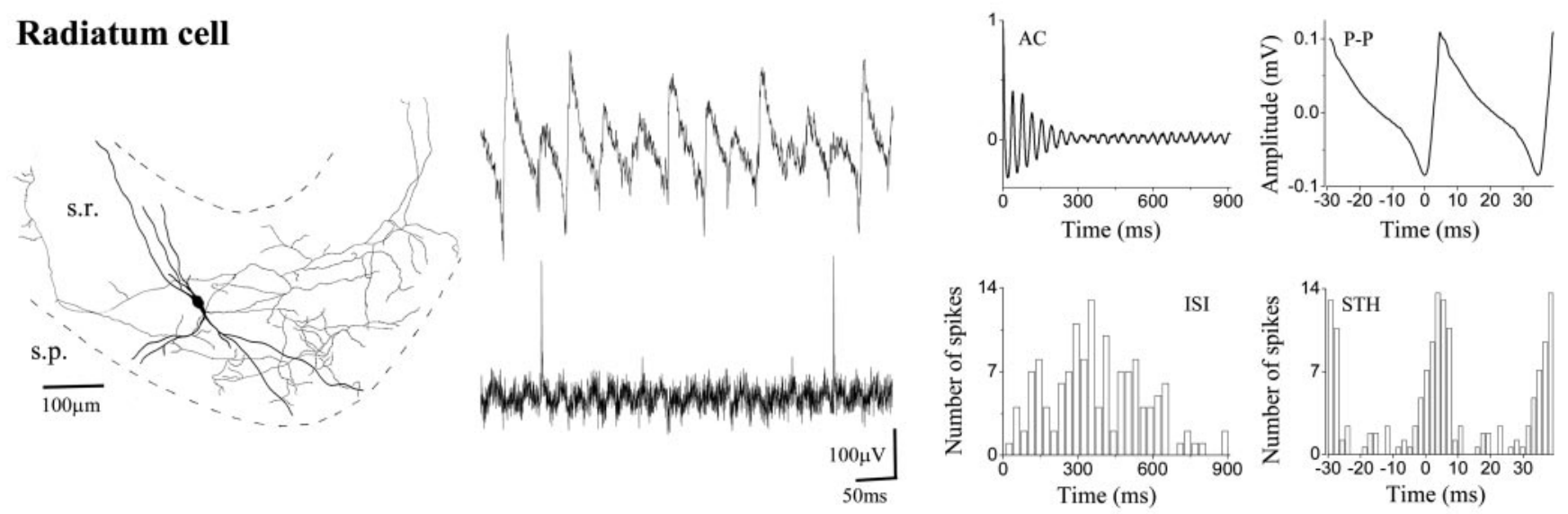

C
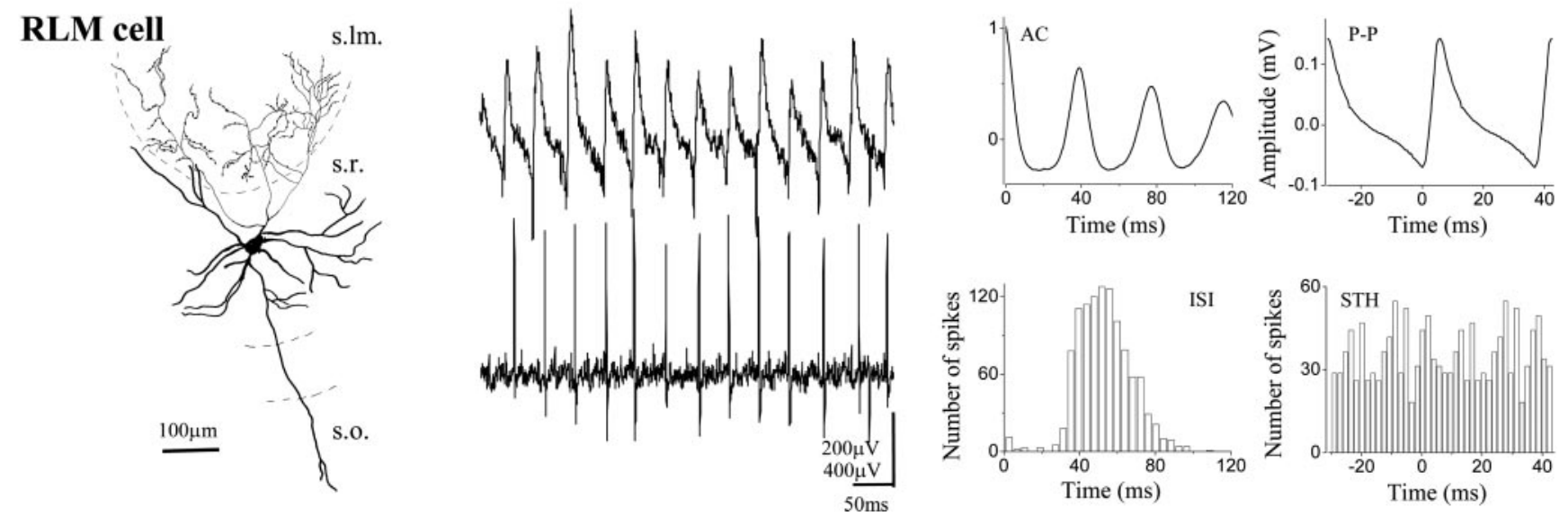

Figure 5. Behavior of dendritic inhibitory interneurons during carbachol-induced network oscillations. Camera lucida reconstructions of an OLM cell ( $A$ ), a radiatum cell ( $B$ ), and an RLM cell ( $C$ are shown. $A$, Both the cell body and the dendritic arbor of the OLM cell were found in the stratum oriens, whereas most of the varicose axon collaterals were restricted to the stratum lacunosum-moleculare. $B$, The dendritic tree, as well as the axon cloud of the radiatum cell, were located in the stratum radiatum. C, The RLM cell with the majority of dendrites in the stratum radiatum exclusively projected to the stratum lacunosum-moleculare. Representative recordings for each cell type demonstrate the different firing characteristics (middle panel). The spike frequency was $15.7 \mathrm{~Hz}$ for the $0 \mathrm{LM}$ cell, $2.5 \mathrm{~Hz}$ for the radiatum cell, and $18.5 \mathrm{~Hz}$ for the RLM cell. The corresponding data calculated from 1-min-long recording epochs are illustrated in the right column. As seen on the STHs compared with the P-P, both the OLM cell and the radiatum cell fired phased-coupled to the oscillations after the negative peak. The ISIs together with ACs indicate that the OLM cell discharged on every second or third cycle, whereas the radiatum cell was much less active. In contrast, the firing of the RLM cell showed no phase relationship indicated by uniform distribution in the spike time histogram, although both the oscillations and the discharge of the neuron were prominent shown by the AC and ISI histogram, respectively. s.Im., Stratum lacunosum-moleculare. 

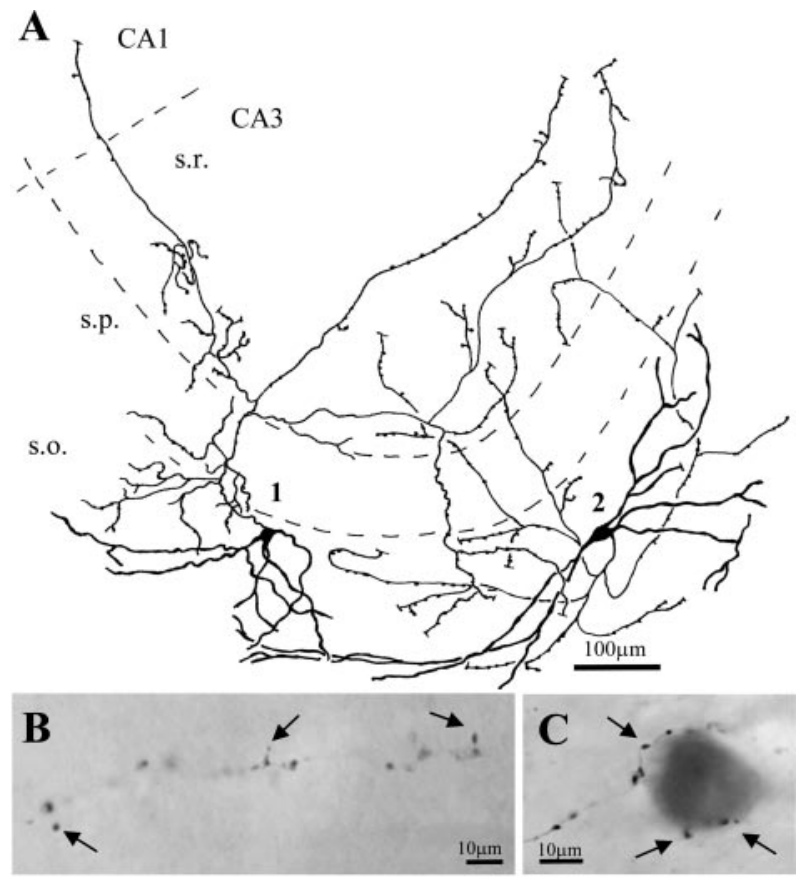

D
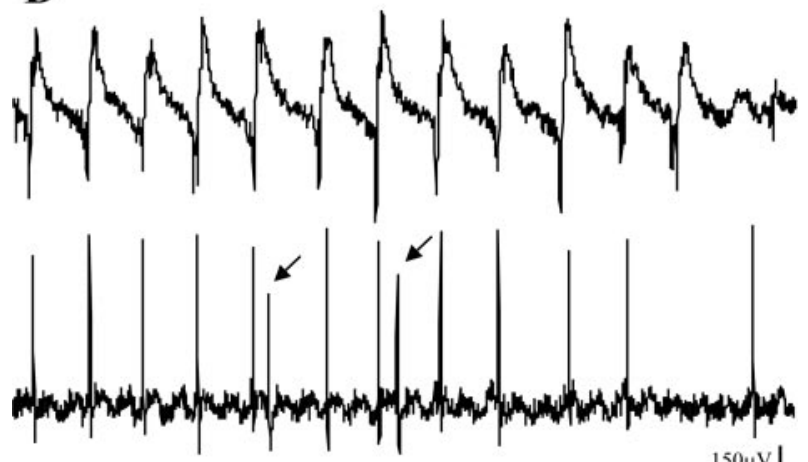

$150 \mu \mathrm{V}$ $300 \mu \mathrm{V}$
$\mathbf{E}$
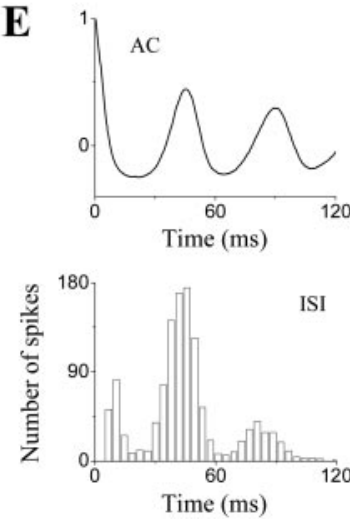
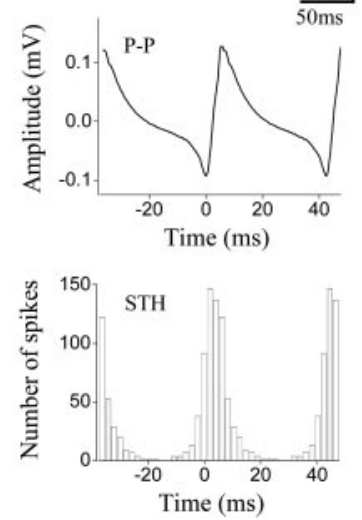

Figure 6. Firing of IS cells is tightly coupled to gamma oscillation. A-C, Light microscopic reconstruction of two intracellularly filled putative IS cells. The cell bodies and the dendritic arbors for both neurons were found in the stratum oriens $(A)$. The main axon originating from the somata gave rise to several collaterals predominantly arborizing in strata oriens and radiatum. Long axon branches reaching the $C A 3 \mathrm{C}$ region as well as penetrating into the CA1 were often decorated by drumstick-like boutons ( $B$, arrows), whereas other varicose collaterals formed multiple appositions (arrows) with nonpyramidal cell bodies in the strata oriens or radiatum (C).D, Raw traces showing the firing activity of cell 2 during the oscillation $(20.8 \mathrm{~Hz})$. Arrows mark the second spike within an oscillation cycle. $E$, Results calculated from a 1-minlong recording epoch showing that the neuron discharged on the ascending phase of the oscillation as indicated on the STH in conjunction with the P-P. Its spiking followed the oscillation with a high fidelity as demonstrated by the ISI together with the AC. greatest delay after the negative peak of the oscillation $(6.23 \pm$ $2.14 \mathrm{msec}$ ) (Fig. 8A,C). The mean angle of the spike times was $128.4 \pm 12.4^{\circ}$ (Fig. $7 E, G$ ) with weak coupling to the oscillations (mean angular SD, $58.3 \pm 7.3^{\circ}$ ) (Fig. $7 F$ ). Those radiatum cells that were not recruited in the synchronous activity had significantly higher firing frequency $(8.7 \pm 1.1 \mathrm{~Hz} ; n=4 ; p<0.01)$. None of the recorded RLM cells showed significant phase coupling (Figs. $5 C, 7 B$ ), but they showed relatively high firing frequency $(13.2 \pm 3.9 \mathrm{~Hz} ; n=4)$ (Figs. $5 C, 7 A$ ).

A third main group of interneurons was identified on the basis of the following light microscopic criteria: (1) long axon collaterals with infrequent branching, sometimes penetrating into the CA1 region (Fig. 6A); (2) axon terminals were irregularly spaced often with drumstick-like appendages (Fig. 6B), and (3) labeled terminals consistently formed close appositions with unlabelled cell bodies outside of the stratum pyramidale resembling GABAergic somata (Fig. 6C). These morphological features were found to be characteristic of interneuron-selective (IS) cells, i.e., interneurons that were shown to selectivity innervate other local GABAergic cells in the hippocampus (Acsády et al., 1996; Gulyás et al., 1996; Gulyás et al., 2003), but were considerably different from horizontal bistratified cells in the stratum oriens (Maccaferri et al., 2000). Based on the criteria described above, we would refer to these neurons as IS cells. According to the laminar distribution of their axons, IS cells belong to the so-called trilaminar cells (Sik et al., 1995), which, however, do not represent a functional category. In addition to IS cells (Gulyás et al., 2003), they appear to include also cells that widely innervate pyramidal neurons (Sik et al., 1995). The light microscopic characteristics of IS cells described above unequivocally distinguish these two cell types with distinct target selectivity. In the present study, IS cells were labeled in the stratum oriens with long dendrites restricted to this layer (Fig. 6A). All but one IS cell fired with high frequency $(18.2 \pm 2.7 \mathrm{~Hz})$ (Figs. $6 D$, $7 A, G)$ and were strongly phase-coupled (Figs. $6 E, 7 B$ ). The spike rate divided by the oscillation frequency was $0.6 \pm 0.09$ (Fig. $7 D$ ), i.e., these neurons also discharged on more than every second cycle of the oscillation. In three cells doublet spikes were also noticed (Fig. $6 D$ ). The average spike time of the first spike for these cells was $1.51 \pm 0.37 \mathrm{msec}$ (Fig. $8 A, C$ ). The mean angle obtained from the bandpass-filtered signal was $96.8 \pm 2.2^{\circ}(n=7)$ (Fig. 7E,G). As indicated by their angular SD $\left(46.1 \pm 5.5^{\circ}\right)$ (Fig. $7 F$ ), IS cells followed the gamma oscillations with high fidelity.

Comparison of the firing phase between interneurons and pyramidal cells revealed that pyramidal cells fired significantly earlier than all types of interneuron (Fig. 7G) (Watson-Williams $F$ test, $p<0.05)$, similar to data obtained in freely moving rat (Csicsvari et al., 2003). In addition, radiatum cells fired significantly later than perisomatic inhibitory cells, OLM cells, and IS cells (Fig. 7G) (Watson-Williams $F$ test; $p<0.05$ ), whereas the firing phase of these latter three cell types was indistinguishable. The average time difference of spiking between pyramidal cells and interneurons (excluding radiatum cells) was $2.1 \pm 0.5 \mathrm{msec}$ $(n=22)$ (Fig. $8 C$ ), consistent with monosynaptic neurotransmission at $30^{\circ} \mathrm{C}$.

\section{Discussion}

The main findings of the present study are the following: (1) long-lasting, temporally stable oscillatory activity can be induced in submerged hippocampal slices; (2) in the carbachol model of gamma oscillations, pyramidal cells fire at the negative peak of 
All neurons

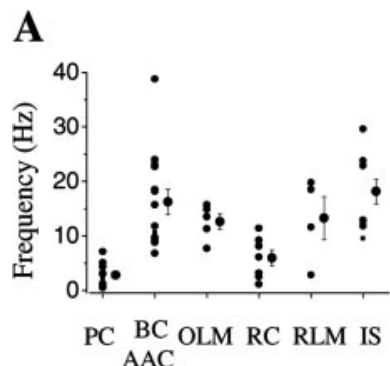

B

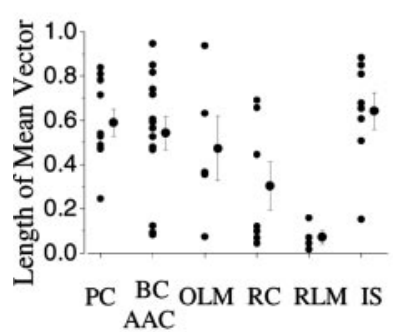

C
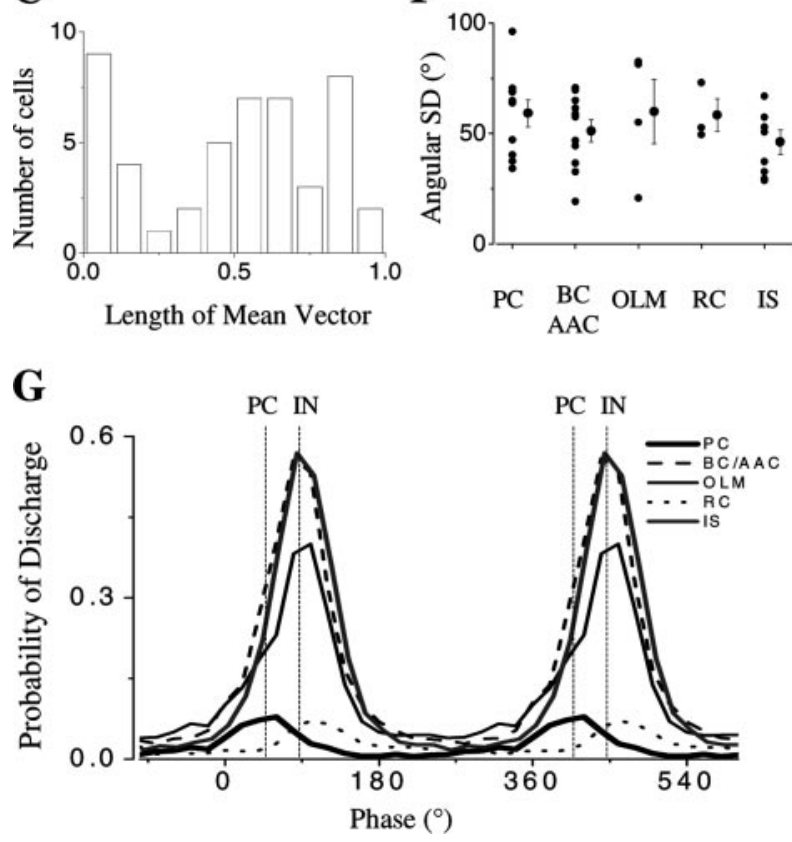

Figure 7. Phase relationship between field oscillations and spiking of identified neurons during cholinergically induced gamma oscillations. $A-C$, Analysis in all neurons. $A, B$, Frequency and length of mean vector plotted for all morphologically identified neurons in each cell category. Note that in all interneuron groups, at least one cell was found not to be significantly phase-coupled. C, Histogram of the length of mean vector, including data for all cells showing a bimodal distribution. Values of the mean vector $<0.2$ suggested a uniform distribution (Rao's spacing test and Rayleigh's uniformity test, $p>0.05)$. Further detailed analysis was performed only on phase-coupled neurons. $D-F$, Firing rate divided by oscillation frequency $(D)$, mean angle $(E)$, and angular SD, indicating the precision of phase-coupling $(F)$ varied substantially among the cell types. Individual points on the plots represent data for individual cells, whereas the mean \pm SEM is indicated on the right for each neuron type. PC, Pyramidal cell; BC, basket cell; $A A C$, axo-axonic cell; OLM, interneurons in the stratum oriens projecting to the stratum lacunosum-moleculare; RC, interneurons with both dendritic and axonal arborizations restricted to the stratum radiatum; RLM, interneurons with dendritic tree in the stratum radiatum projecting into the stratum lacunosum-moleculare; IS, cells with morphological appearance resembling interneuron-selective interneurons. $G$, Average phase histograms of unit activity during gamma oscillations showing that PC discharge is followed by discharge of the various types of interneuron (IN). Dotted vertical lines indicate the mean of the mode of the phase angle for pyramidal cells and all classes of interneurons, respectively.
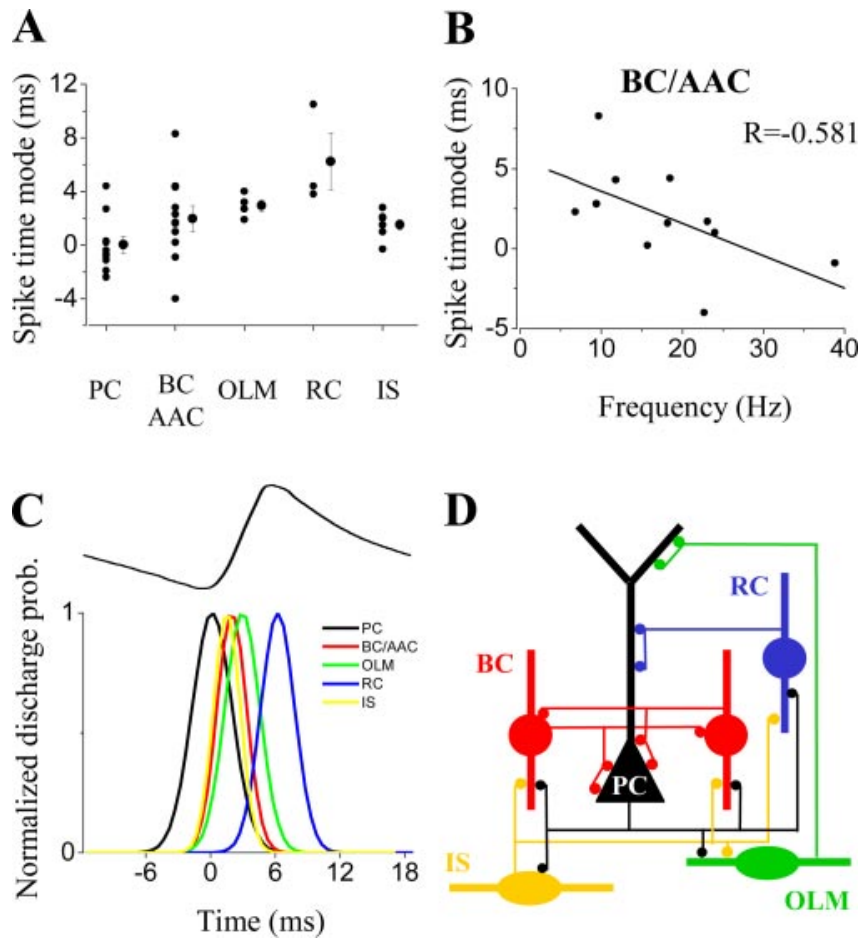

Figure 8. Time relationship between field potentials and spiking activity of identified hippocampal neurons during oscillations. $A$, Mode of the spike time histograms relative to the time of the negative peak of the average oscillation plotted for the different types of hippocampal neurons. The individual points on the plot represent data for individual cells, whereas the mean $\pm S E M$ is indicated on the right for each type of neuron. $B$, Negative correlation between the rate of firing of individual perisomatic inhibitory neurons (basket and axo-axonic cells) and their relative spike times. Cells with higher discharge rate tend to fire closer to the negative peak. C, Time sequence of firing of different neuron types during an oscillatory cycle. Top trace shows representative average field oscillatory wave. Pyramidal cells fired at the negative peak of the oscillation followed by the interneurons. Gaussian functions were fitted to the spike time distribution for each type of neuron, and the average mean and SD were used to represent each cell class as a Gaussian function. D, Schematic diagram of the connectivity among phase-coupled neuron types in the CA3 hippocampal circuitry taking part in the gamma oscillation.

the oscillations followed by the discharge of interneurons; and (3) perisomatic inhibitory neurons and IS cells are the most active cell types during this type of oscillation with strong phase coupling, whereas dendritic-targeting interneurons show less or sometimes no significant phase coupling.

Previous in vitro studies showed that gamma-frequency network oscillations lasting for tens of minutes could be routinely induced in hippocampal slices in an interface-type of recording chamber (Whittington et al., 1995; Boddeke et al., 1997; Fisahn et al., 1998; Pálhalmi et al., 2004). In contrast, oscillations evoked in submerged-type of slice chambers, designed for visually guided patch-clamp recordings using infrared DIC optics, lasted for only some seconds and were qualitatively different from those recorded in interface conditions (McMahon et al., 1998; Kawaguchi, 2001). Here, we combine the advantages of both techniques, i.e., maintenance of longlasting stable oscillations with visualization of individual neurons, by improving the recording conditions in submerged chamber to allow us to study the behavior of different types of neuron during network oscillations. The possibility of obtaining stable oscillations for $>1 \mathrm{hr}$ suggests that these conditions may be appropriate for exploring many aspects of network physiology in vitro. 
Different in vitro models of gamma oscillations have been introduced that suggest that distinct mechanisms could lead to fast synchronous oscillatory activity in the hippocampal subfields. In the CA1 region, but not in CA3, both chemically and electrically interconnected interneuronal networks could generate $40 \mathrm{~Hz}$ oscillations without any contribution of pyramidal cells (Whittington et al., 1995; Boddeke et al., 1997; Hormuzdi et al., 2001; Traub et al., 2001a). On the other hand, different protocols that excite both pyramidal cells and interneurons (Fisahn et al., 1998; LeBeau et al., 2002; Cunningham et al., 2003; Pálhalmi et al., 2004) were found to induce in vitro gamma oscillations in both CA1 and CA3, implying that synchronization could also occur as an interplay between excitatory cells and GABAergic interneurons. Both in vitro and in vivo studies (Fisahn et al., 1998; Csicsvari et al., 2003; Pálhalmi et al., 2004) suggested that during gamma oscillations in CA3, pyramidal cells drive local interneurons in a feedback manner. Here we tested predictions of this hypothesis by measuring the firing properties and phase relationship of anatomically identified interneurons and compared them to those of pyramidal cells. Our data show that most interneuron subtypes do indeed discharge with a delay after pyramidal cells consistent with monosynaptic transmission. Although our values are somewhat different from those predicted by a study in the olfactory system (Eeckman and Freeman, 1990), they are in good agreement with data obtained in the hippocampus of freely moving rats (Csicsvari et al., 2003).

In addition, our experiments revealed that functionally distinct interneuron subtypes show different firing properties during in vitro oscillations. Perisomatic inhibitory interneurons were found to fire with high discharge rate, strongly phase-coupled to the network oscillation. In contrast, OLM cells showed phase-coupled firing at somewhat lower frequency, whereas the majority of interneurons in the stratum radiatum targeting the dendritic region of pyramidal cells (radiatum and RLM cells) did not show significant phase-related firing. Cells belonging to a third functional category of GABAergic neurons, the IS cells, which share several morphological similarities with GABAergic cells projecting to the medial septum (Gulyás et al., 2003), also fired with high discharge rate, tightly locked to the oscillation. This heterogeneity in the firing patterns of different types of interneuron raises the question of what is the main determining factor of their distinct behavior. One explanation might be that different interneurons have a distinct firing preference for a given oscillatory input. As suggested by Pike et al. (2000), hippocampal fastspiking cells (corresponding, at least partly, to perisomatic inhibitory cells) are "tuned" to gamma frequency range. In contrast, some cells in stratum oriens (that may correspond to OLM cells) as well as pyramidal cells showed firing preference at $\theta$ frequencies. Our results showed that perisomatic inhibitory cells can follow gamma oscillations with high fidelity, whereas OLM cells and pyramidal cells fired at a lower rate, suggesting that intrinsic membrane properties might indeed contribute to the different firing properties during oscillations.

Another explanation for the heterogeneity in firing might be that excitatory input from CA3 pyramidal cells could drive interneurons with different efficacy. Given that the axons of CA3 pyramidal cells first enter the stratum oriens where they give rise to all their recurrent collaterals, some of which turn to penetrate into the stratum radiatum projecting toward the CA1 region (Sik et al., 1993; Li et al., 1994), one might assume that in slices, the chance of preserving intact axon collaterals from pyramidal cells in the stratum oriens is higher than in the stratum radiatum. In fact, we found that the vast majority of interneurons in the stratum oriens were phase-coupled $(86 \%$; 56 of 65 ), whereas $<50 \%$ of the neurons in the strata radiatum or lucidum had any phase relationship (44\%; 14 of 32 ), regardless of the axon arborization pattern. The timing and the kinetics of excitation received by different interneuron types could also contribute to their distinct firing reliability and frequency (Jonas et al., 2004; Pouille and Scanziani, 2004). Studies are underway to establish whether the intrinsic properties of interneurons or the magnitude and integration of synaptic input are the more important factors in determining firing properties during network oscillations.

The finding that most interneurons in carbachol-induced oscillations were excited in a feedback manner raises the question of which inhibitory cell types are more important for synchronization. We suggest that perisomatic inhibitory cells, including both basket and axo-axonic cells, are in a key position to synchronize the network, because they effectively control spike timing of pyramidal cells (Cobb et al., 1995; Miles et al., 1996), which in turn could reliably excite them via monosynaptic connections (Gulyás et al., 1993; Sik et al., 1993). Thus, a pyramidal cell-perisomatic inhibitory neuron loop could generate fast oscillations in the CA3 network, as suggested by modeling studies (Traub et al., 2000). These suggestions are also supported by the results obtained with CSD analysis, which showed periodic sources in the stratum pyramidale after the peak discharge phase of perisomatic inhibitory interneurons. Conversely, there were no dendritic current sources that could be attributed to fast inhibition after the peak discharge of dendritic interneurons. Indeed, the firing phase and frequency of pyramidal cells and inhibitory interneurons imply that sinks and sources in the stratum pyramidale are active processes paralleled by passive currents in proximal stratum radiatum. Another question relates to the events that terminate the firing of basket cells after discharging a single spike (or sometimes doublets). The control of basket cell firing might derive from two independent sources. First, it has been shown that basket cells are mutually interconnected (Sik et al., 1995; Klausberger et al., 2002) and communicate via IPSCs of large amplitude and fast kinetics (Bartos et al., 2002), providing a possibility to effectively regulate the firing of one another. Second, IS cells, another cell type that fired tightly coupled to the oscillation, may also be able to terminate the firing of perisomatic inhibitory neurons (Fig. 8D).

Several studies showed (for review, see Traub et al., 2001b) that bath application of carbachol could induce seizure-like activity in hippocampal slices. Under our circumstances, appearance of interictal spikes was present in $<5 \%$ of slices in conjunction with gamma oscillations. These slices were excluded from the study.

A comparison of in vitro gamma oscillations induced by carbachol in the CA3 region of hippocampal slices with those obtained in freely moving animals (Bragin et al., 1995; Csicsvari et al., 2003) reveals striking similarities. First, the origin of gamma oscillations is intrinsic to the CA3 neuronal network (Fisahn et al., 1998). Second, there is a phase reversal in stratum lucidum of CA3 (Fig. 2C) (Fisahn et al., 1998; Shimono et al., 2000). Third, CA3 pyramidal cell firing is followed by the discharge of CA3 interneurons with a delay consistent with monosynaptic transmission (present study). These observations suggest that carbachol-induced oscillations in the CA3 region represent a physiologically relevant model and can be used to study the cellular mechanisms underlying the generation, maintenance, and 
termination of synchronous activity at $40 \mathrm{~Hz}$. It should be noted, however, that gamma oscillations recorded in other regions of the hippocampus may rely on different mechanisms, because neuronal circuitries of the CA3 subfield have some unique features such as the recurrent collateral system.

In summary, in the cholinergic model of gamma oscillations, recurrent excitation of inhibitory interneurons by CA3 pyramidal cells could give rise to synchronization of the local neuronal network (Fig. 8D). Based on previous data and our current results, perisomatic inhibitory cells are likely to play an instrumental role during gamma oscillations by controlling the precise timing of firing of pyramidal cell assemblies.

\section{References}

Acsády L, Gorcs TJ, Freund TF (1996) Different populations of vasoactive intestinal polypeptide-immunoreactive interneurons are specialized to control pyramidal cells or interneurons in the hippocampus. Neuroscience 73:317-334.

Bartos M, Vida I, Frotscher M, Meyer A, Monyer H, Geiger JR, Jonas P (2002) Fast synaptic inhibition promotes synchronized gamma oscillations in hippocampal interneuron networks. Proc Natl Acad Sci USA 99:13222-13227.

Boddeke HW, Best R, Boeijinga PH (1997) Synchronous $20 \mathrm{~Hz}$ rhythmic activity in hippocampal networks induced by activation of metabotropic glutamate receptors in vitro. Neuroscience 76:653-658.

Bragin A, Jando G, Nadasdy Z, Hetke J, Wise K, Buzsáki G (1995) Gamma $(40-100 \mathrm{~Hz})$ oscillation in the hippocampus of the behaving rat. J Neurosci 15:47-60.

Buzsáki G, Chrobak JJ (1995) Temporal structure in spatially organized neuronal ensembles: a role for interneuronal networks. Curr Opin Neurobiol 5:504-510.

Chrobak JJ, Buzsáki G (1998) Gamma oscillations in the entorhinal cortex of the freely behaving rat. J Neurosci 18:388-398.

Cobb SR, Buhl EH, Halasy K, Paulsen O, Somogyi P (1995) Synchronization of neuronal activity in hippocampus by individual GABAergic interneurons. Nature 378:75-78.

Cunningham MO, Davies CH, Buhl EH, Kopell N, Whittington MA (2003) Gamma oscillations induced by kainate receptor activation in the entorhinal cortex in vitro. J Neurosci 23:9761-9769.

Csicsvari J, Jamieson B, Wise KD, Buzsáki G (2003) Mechanisms of gamma oscillations in the hippocampus of the behaving rat. Neuron 37:311-322.

Eeckman FH, Freeman WJ (1990) Correlations between unit firing and EEG in the rat olfactory system. Brain Res 528:238-244.

Engel AK, Fries P, Singer W (2001) Dynamic predictions: oscillations and synchrony in top-down processing. Nat Rev Neurosci 2:704-716.

Fell J, Klaver P, Lehnertz K, Grunwald T, Schaller C, Elger CE, Fernandez G (2001) Human memory formation is accompanied by rhinalhippocampal coupling and decoupling. Nat Neurosci 4:1259-1264.

Fisahn A, Pike FG, Buhl EH, Paulsen O (1998) Cholinergic induction of network oscillations at $40 \mathrm{~Hz}$ in the hippocampus in vitro. Nature 394:186-189.

Freund TF, Buzsáki G (1996) Interneurons of the hippocampus. Hippocampus 6:347-470.

Fries P, Reynolds JH, Rorie AE, Desimone R (2001) Modulation of oscillatory neuronal synchronization by selective visual attention. Science 291:1560-1563.

Gray CM (1994) Synchronous oscillations in neuronal systems: mechanisms and functions. J Comput Neurosci 1:11-38.

Gulyás AI, Miles R, Sik A, Toth K, Tamamaki N, Freund TF (1993) Hippocampal pyramidal cells excite inhibitory neurons through a single release site. Nature 366:683-687.

Gulyás AI, Hájos N, Freund TF (1996) Interneurons containing calretinin are specialized to control other interneurons in the rat hippocampus. J Neurosci 16:3397-3411.

Gulyás AI, Hájos N, Katona I, Freund TF (2003) Interneurons are the local targets of hippocampal inhibitory cells which project to the medial septum. Eur J Neurosci 17:1861-1872.

Hájos N, Mann EO, Freund TF, Paulsen O (2004) Increased oxygen supply enables cholinergically-induced network oscillations in submerged hippocampal slices. Fed European Neurosci Soc Abstr 2:A009.013.
Hasselmo ME, Wyble BP, Wallenstein GV (1996) Encoding and retrieval of episodic memories: role of cholinergic and GABAergic modulation in the hippocampus. Hippocampus 6:693-708.

Hormuzdi SG, Pais I, LeBeau FE, Towers SK, Rozov A, Buhl EH, Whittington MA, Monyer H (2001) Impaired electrical signaling disrupts gamma frequency oscillations in connexin 36-deficient mice. Neuron 31:487-495.

Jonas P, Bischofberger J, Fricker D, Miles R (2004) Interneuron diversity series: fast in, fast out-temporal and spatial signal processing in hippocampal interneurons. Trends Neurosci 27:30-40.

Kawaguchi Y (2001) Distinct firing patterns of neuronal subtypes in cortical synchronized activities. J Neurosci 21:7261-7272.

Klausberger T, Roberts JD, Somogyi P (2002) Cell type- and input-specific differences in the number and subtypes of synaptic GABA(A) receptors in the hippocampus. J Neurosci 22:2513-2521.

Klausberger T, Magill PJ, Marton LF, Roberts JD, Cobden PM, Buzsáki G, Somogyi P (2003) Brain-state- and cell-type-specific firing of hippocampal interneurons in vivo. Nature 421:844-848.

Klausberger T, Marton LF, Baude A, Roberts JD, Magill PJ, Somogyi P (2004) Spike timing of dendrite-targeting bistratified cells during hippocampal network oscillations in vivo. Nat Neurosci 7:41-47.

LeBeau FE, Towers SK, Traub RD, Whittington MA, Buhl EH (2002) Fast network oscillations induced by potassium transients in the rat hippocampus in vitro. J Physiol (Lond) 542:167-179.

Leung SW (1979) Potentials evoked by alvear tract in hippocampal CA1 region of rats. II. Spatial field analysis. J Neurophysiol 42:1571-1589.

Li XG, Somogyi P, Ylinen A, Buzsáki G (1994) The hippocampal CA3 network: an in vivo intracellular labeling study. J Comp Neurol 339:181-208.

Maccaferri G, Roberts JD, Szucs P, Cottingham CA, Somogyi P (2000) Cell surface domain specific postsynaptic currents evoked by identified GABAergic neurones in rat hippocampus in vitro. J Physiol (Lond) 524: 91-116.

Marrosu F, Portas C, Mascia MS, Casu MA, Fa M, Giagheddu M, Imperato A, Gessa GL (1995) Microdialysis measurement of cortical and hippocampal acetylcholine release during sleep-wake cycle in freely moving cats. Brain Res 671:329-332.

McMahon LL, Williams JH, Kauer JA (1998) Functionally distinct groups of interneurons identified during rhythmic carbachol oscillations in hippocampus in vitro. J Neurosci 18:5640-5651.

Miles R, Toth K, Gulyás AI, Hájos N, Freund TF (1996) Differences between somatic and dendritic inhibition in the hippocampus. Neuron 16:815-823.

Oka H, Shimono K, Ogawa R, Sugihara H, Taketani M (1999) A new planar multielectrode array for extracellular recording: application to hippocampal acute slice. J Neurosci Methods 93:61-67.

Pálhalmi J, Paulsen O, Freund TF, Hájos N (2004) Distinct properties of carbachol- and DHPG-induced network oscillations in hippocampal slices. Neuropharmacology 47:381-389.

Paulsen O, Moser EI (1998) A model of hippocampal memory encoding and retrieval: GABAergic control of synaptic plasticity. Trends Neurosci 21:273-278.

Pike FG, Goddard RS, Suckling JM, Ganter P, Kasthuri N, Paulsen O (2000) Distinct frequency preferences of different types of rat hippocampal neurones in response to oscillatory input currents. J Physiol (Lond) 529: 205-213.

Pouille F, Scanziani M (2004) Routing of spike series by dynamic circuits in the hippocampus. Nature 429:717-723.

Shimono K, Brucher F, Granger R, Lynch G, Taketani M (2000) Origins and distribution of cholinergically induced beta rhythms in hippocampal slices. J Neurosci 20:8462-8473.

Sik A, Tamamaki N, Freund TF (1993) Complete axon arborization of a single CA3 pyramidal cell in the rat hippocampus, and its relationship with postsynaptic parvalbumin-containing interneurons. Eur J Neurosci 5:1719-1728

Sik A, Penttonen M, Ylinen A, Buzsáki G (1995) Hippocampal CA1 interneurons: an in vivo intracellular labeling study. J Neurosci 15:6651-6665.

Singer W (1993) Synchronization of cortical activity and its putative role in information processing and learning. Annu Rev Physiol 55:349-374.

Soltesz I, Bourassa J, Deschenes M (1993) The behavior of mossy cells of the 
rat dentate gyrus during theta oscillations in vivo. Neuroscience 57:555-564.

Traub RD, Bibbig A, Fisahn A, LeBeau FE, Whittington MA, Buhl EH (2000) A model of gamma-frequency network oscillations induced in the rat CA3 region by carbachol in vitro. Eur J Neurosci 12:4093-4106.

Traub RD, Kopell N, Bibbig A, Buhl EH, LeBeau FE, Whittington MA (2001a) Gap junctions between interneuron dendrites can enhance synchrony of gamma oscillations in distributed networks. J Neurosci 21:9478-9486.

Traub RD, Whittington MA, Buhl EH, LeBeau FE, Bibbig A, Boyd S, Cross H, Baldeweg T (2001b) A possible role for gap junctions in generation of very fast EEG oscillations preceding the onset of, and perhaps initiating, seizures. Epilepsia 42:153-170.
Varela F, Lachaux JP, Rodriguez E, Martinerie J (2001) The brainweb: phase synchronization and large-scale integration. Nat Rev Neurosci 2:229-239.

Whittington MA, Traub RD (2003) Interneuron diversity series: inhibitory interneurons and network oscillations in vitro. Trends Neurosci 26:676-682.

Whittington MA, Traub RD, Jefferys JG (1995) Synchronized oscillations in interneuron networks driven by metabotropic glutamate receptor activation. Nature 373:612-615.

Ylinen A, Soltesz I, Bragin A, Penttonen M, Sik A, Buzsáki G (1995) Intracellular correlates of hippocampal theta rhythm in identified pyramidal cells, granule cells, and basket cells. Hippocampus 5:78-90. 